\title{
PROCESOS ECO TERRITORIALES EN LA OCUPACIÓN DEL DESIERTO SUR OCCIDENTAL DEL PERÚ
}

\author{
ECO TERRITORIAL PROCESSES IN THE OCCUPATION OF THE SOUTHERN \\ OCCIDENTAL DESERT OF PERU
}

${ }^{1}$ Gustavo José Becerra Moscoso

\begin{abstract}
RESUMEN
Los espacios naturales no siempre son valorizados en su verdadera dimensión desde un punto de vista ambiental y de aporte positivo al hábitat del hombre. Es así que los desiertos son considerados como lugares que no tienen valor, son áreas naturales propicias a ser ocupadas en forma irregular y sin consideración a su función en los ecosistemas integrados. En el Perú, los procesos de la ocupación territorial se efectúan de manera no planificada, generando asentamientos poblacionales informales, a excepción de los proyectos formalizados de irrigaciones a cargo del Ministerio de Agricultura y otras instancias. Estos procesos han representado en la faja costera de Perú, sobre todo en la parte sur occidental, una concurrencia de aciertos y errores, de planificación e invasión en estos espacios, con efectos en el medio ambiente y en el campo socioeconómico. El objetivo del presente estudio es alertar a las autoridades, a fin de que adopten las previsiones medio ambientales necesarias para evitar su colapso, por las ocupaciones informales, que se han venido produciendo desde la segunda mitad del siglo pasado. Como ámbito contextual se considera, las fajas costeras de los desiertos entre Arequipa, Moquegua y Tacna. Por otro lado, como muestra de análisis expuesto a indicadores e instrumentos, se considera las irrigaciones del desierto centro de la región Arequipa, incluyendo el caso inédito del Proyecto Majes, que responde en parte, a las acciones previamente planificadas en los niveles medio ambientales, espaciales, sociales y legales, siendo una buena opción la gestión compartida entre los gobiernos de dichas regiones.
\end{abstract}

Palabras clave: Desierto, ecosistema, irrigación, proceso, territorio.

\begin{abstract}
Natural spaces are not always valued in their true dimension from an environmental point of view and positive contribution to the habitat of man. Thus, deserts are considered places that have no value; they are natural areas conducive to being occupied in an irregular manner and without regard to their role in integrated ecosystems. In Peru, the processes of territorial occupation are carried out in an unplanned manner, generating informal population settlements, with the exception of formalized irrigation projects by the Ministry of Agriculture and other agencies. These processes have represented on the coastal strip of Peru, especially in the south western part, a concurrence of successes and errors, of planning and invasion in these spaces, with effects in the environment and in the socioeconomic field. The objective of this study is to alert the authorities, so that they could adopt the necessary environmental precautions to avoid their collapse, due to the informal occupations that have been taking place since the second half of the last century. As contextual context is considered, the coastal strips of the deserts between Arequipa, Moquegua and Tacna. On the other hand, as a sample of analysis exposed to indicators and instruments, the irrigations of the desert center of the Arequipa region are considered, including the unpublished case of the Majes Project, which responds in part to the actions previously planned at environmental levels, spatial, social and legal, being a good option shared management among the governments of these regions.
\end{abstract}

Keywords: Desert, ecosystem, irrigation, process, territory. 


\section{INTRODUCCIÓN}

El presente tema de estudio tiene como motivación aportar a la problemática de los procesos ecoterritoriales en el espacio de la zona sur occidental del Perú, porque no hay una demarcación precisa de la intervención territorial. Los "mapas geológicosambientales" son herramientas para la planificación, y la unidad de recursos del medio ambiente, representa la base para el ordenamiento (Miró y Morato, 1984), ya que representan el grado de impacto de las actividades humanas en los ecosistemas del territorio. En este caso, dichos grados corresponden a los últimos 50 años del siglo $\mathrm{XX}$ dentro del espacio costero sur del Perú. En dicho período, se produjeron las ocupaciones más significativas y la dación de dispositivos sectoriales y gubernamentales de mayor trascendencia normativa.

La dimensión del tema es compleja y de carácter interregional, el proceso del ordenamiento del territorio se demarca en el contexto de globalización que expresa el orden económico internacional, lo que debe representar premisas para el diseño y políticas de ordenamiento (Massiris, 2012); con ello, se posibilita que se consensue acciones en lo ecológico, ambiental, social, económico, productivo, también en lo paisajístico.

Este tema busca identificar los procesos eco territoriales en los últimos 50 años del siglo pasado, que se han originado desde la zona costera norte de la región de Arequipa, provincia de Caravelí, hasta el desierto costero del departamento de Tacna, en la frontera con Chile, y que longitudinalmente abarca más de $700 \mathrm{~km}$ paralelos a la faja de litoral sur peruano, abarca porciones territoriales de cabecera del gran desierto de Atacama, el más árido del mundo, y que en Chile toma dimensiones mundiales como destino turístico de primer nivel; más este gran espacio, ha sido ocupado, alterado, y hasta degradado ambientalmente de diversas formas, y que lejos de inscribirse normativamente, altera el paisaje geomorfológico original $y$ afecta la calidad edafológica del suelo.

En resumen, el objetivo del estudio pretende marcar en el tiempo y espacio los procesos eco territoriales que se dieron en la segunda mitad del siglo XX, en este espacio calificado como desierto, y llamar la atención de la comunidad sur del Perú, a fin de adoptar decisiones ambientales amistosas y responsables con el desierto; pero, esto es tarea de todos, potenciando los recursos para la sensibilización, y diseñar políticas audaces para hacer que el desierto sea vigente y receptivo. Landsberg (en Golany, 1993) pondera que aunque las tierras desérticas nos pueden parecer muy pacíficas; sin embargo, contienen el paso de vientos que soplan fuerte, generando una inestabilidad, según los meteorólogos.
La oferta de planificación hacia los espacios desérticos en el Perú han sido diversas, pero con emisiones normativas a destiempo. En la tipología de planificaciones en el país, se establecía que la de tipo imperativo correspondía a los sectores públicos y la de tipo indicativo o normativo para el sector privado, y de carácter general para sectores económicosociales (Meneses, 1998); en este contexto, el estudio representa una aproximación reflexiva, se ha focalizado el tema en las ocupaciones del espacio desértico en los proyectos de irrigaciones del centro oeste de la región Arequipa, como La Cano y San Camilo, y procesos de asentamiento del Proyecto Majes al año 2000.

\section{Problemática}

De acuerdo con el concepto eco sistémico, territorio es el espacio físico en el que se desenvuelven el conjunto de actividades humanas con los elementos del medio natural que lo conforman, o como Santos (en Muñoz, 2011) define: "[ ] El territorio no es sólo el resultado de la superposición de un conjunto de sistemas naturales y un conjunto de sistemas de cosas creadas por el hombre. El territorio es el piso más la población, esto es, una identidad, el hecho y el sentimiento de pertenecer a aquello que nos pertenece

[]".

En este escenario territorial definido, se aprecia la problemática del desierto costero sur, donde la interacción del poblador sur peruano con el conjunto de condiciones físicas y biológicas del medio natural que conforman el ecosistema del desierto indicado, han marcado los procesos eco territoriales de su ocupación, sobre todo informal o ilegítima, no han representado a la fecha una resultante medio ambiental y formal que sea amistosa con el medio ambiente y el paisaje. El suelo y el espacio no deben ser vistos como una mercancía, es preciso que se definan políticas a fin de que el territorio de la ciudad, sea cada vez menos un negocio privado y si un bien social (Cárdenas, 1999). En este contexto, las inversiones privadas generaron un proceso espontáneo en la ocupación del espacio y posteriormente, se regularizaron dichas ocupaciones frente al estado.

Estos procesos, han tenido su contraparte en ocupaciones no formalizadas llamadas invasiones por capturar territorios en forma irregular, localizándose en zonas marginales a centros de atracción económica, entendiendo que todo territorio forma parte de un ecosistema que brinda y provee servicios y recursos naturales, los cuales son aprovechados para atender diversas necesidades y dar bienestar a la población, constituyen entonces, una base del desarrollo productivo múltiple $\mathrm{y}$ potencial. La problemática expone marcos referenciales de índole técnico-legal, social y espacial que permiten ubicar el nivel de análisis contextual y de territorio de los desiertos de Arequipa, Moquegua y Tacna. 


\section{Objetivo}

El propósito del tema es contextualizar dentro de una aproximación deductiva espacial, la identificación general de los principales procesos de ocupación eco territorial en la zona geográfica de desierto sur del Perú, segunda mitad del siglo XX, que permita dimensionar el grado de los impactos en la ocupación del territorio respecto a los normativos vigentes.

\section{MATERIAL Y MÉTODOS}

Para el tema se ha demarcado el estudio por los contextos básicos que el tema implica y que resume la problemática en forma desagregada de estudio planes y sus unidades contextuales. Los planes deben cumplir con procedimientos de naturaleza lineal, definiendo "Misión" y la supuesta "Visión", del ámbito o contexto geográfico a intervenir (González, 2011).

\section{Contexto eco sistémico}

Para formular previamente el problema central, que es complejo, se encuentra una analogía entre la ocupación de las ciudades y de los territorios: La ciudad se ve como un sistema dinámico, cuya evolución da respuesta a muchas influencias, deduciendo que los planes sobre la ciudad deben estar calculados similarmente (McLoughlin, 1971).

Se sostiene que la preferencia y atención de las decisiones se dirigen más a los llamados cuerpos de agua, a los grandes bosques y florestas amazónicas y no se valoró a los planes, como una prioridad para la conservación ambiental desde un punto de vista de sostenibilidad; sin embargo, se debe citar otros ecosistemas similares en su importancia; pero, con resultados diferentes en cuanto a su ocupación y preservación, siendo estos los desiertos del mundo (figura 1) y muchos apreciados solo como espacios sin vida y sin valor; quizá porque siempre se los asoció a lo inerte y árido, pero contienen una vegetación de plantas primarias en conglomerados de líquenes, gramadales y tilansiales, que ya están desapareciendo del planeta, y los del tipo secano, como los de Sonora o Chihuahua entre México y Estados Unidos.

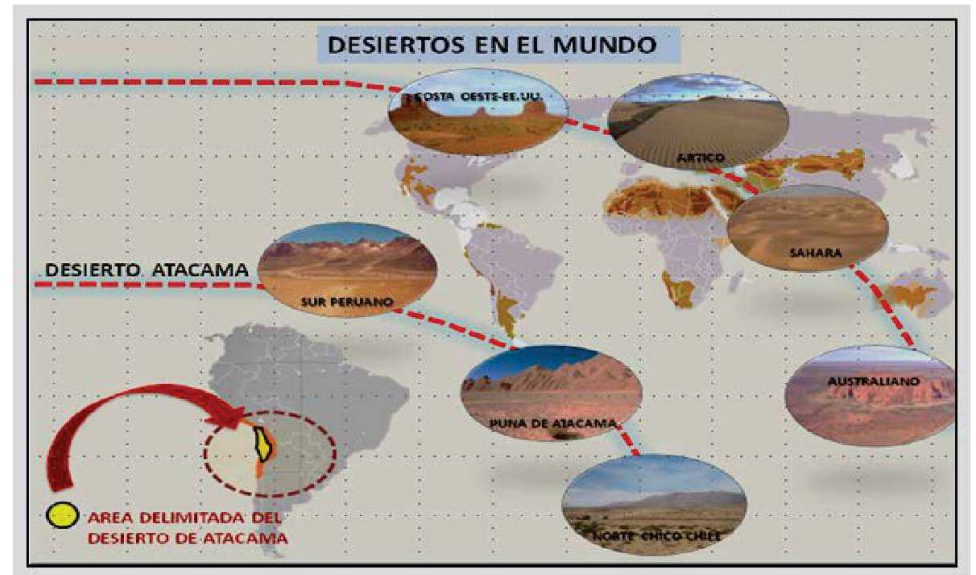

Figura 1. Localización de los grandes desiertos en el mundo. Ubicación contextual del área de estudio Fuente: Base Google

Los desiertos en el mundo, según la ONU al año 2006, ocupaban aproximadamente una cuarta parte de la superficie del planeta y el $8 \%$ de la población mundial aproximadamente (unos 500 millones de personas) viven en los mismos o en sus márgenes; estas poblaciones migran estacionalmente, su recinto casi permanente es este ecosistema, muchas sin el confort de las ciudades. El desierto del Sahara, es el más cálido y grande del mundo, después de los desiertos de hielo Ártico y Antártico, con 9200000 $\mathbf{k m}^{2}$; en esta tipología de desierto, se registra el de Atacama, el más árido y seco del mundo, según la National Geographic, comprende en mayor parte, el norte de Chile y en la parte sur del Perú, se inicia en la costa de Ica, como parte de la cabecera de este desierto. El tramo total entre Perú y Chile es de 2400 $\mathrm{km}$ aproximadamente, correspondiendo a Chile 1600 $\mathrm{km}$ y a Perú $800 \mathrm{~km}$, respectivamente.
La superficie considerada dentro del territorio chileno es de $105000 \mathrm{~km}^{2}$, y para el caso del Perú, considerando el espacio costero entre el nivel del mar y la costa es de 1800 m.s.n.m. Entre las regiones de Arequipa, Moquegua y Tacna, tenemos una superficie de $17016 \mathrm{~km}^{2}$, aproximadamente (figura 2). En este último escenario, se ubican las planicies costeras inscritas en el desierto costero del sur del Perú, ubicado en la zona sur occidental.

\section{Contexto físico espacial}

El estudio se enmarca en un área que abarca, en su mayor parte, en las áreas desérticas de las regiones de Arequipa, Moquegua y Tacna, que se denominará desierto sur occidental del Perú. Esta región de la costa, ubicada entre los 0 y 2000 m.s.n.m. se caracteriza por la ausencia de lluvias durante todo el año. 
El área de estudio contextual implica insertar la misma en un contexto mayor. Las relaciones urbanoregionales y las urbano-rurales, están en función de la disposición de los asentamientos, los vínculos entre sus flujos, de la ocupación y asentamiento poblacional en el uso de suelo, generando la dinámica entre los componentes territoriales (Alcaldía de Medellín, 2014). La población urbana y rural de la costa utiliza el agua de una media centena de ríos de régimen irregular $\mathrm{y}$ con un marcado carácter estacional en múltiples actividades agrícolas, de consumo humano e industriales. Entre las regiones de Arequipa, Moquegua y Tacna, se tiene una superficie, como se indicó, de $17016 \mathrm{~km}^{2}$, aproximadamente (figuras 2 y 3 ).

En este último escenario, se instalan las planicies costeras ubicadas en el desierto costero del sur del Perú, zona sur occidental, donde se advierte la relativa planificación y control territorial de los órganos de gestión por la preservación y sostenibilidad de este espacio, con demarcación de intangibilidad en áreas de protección natural.

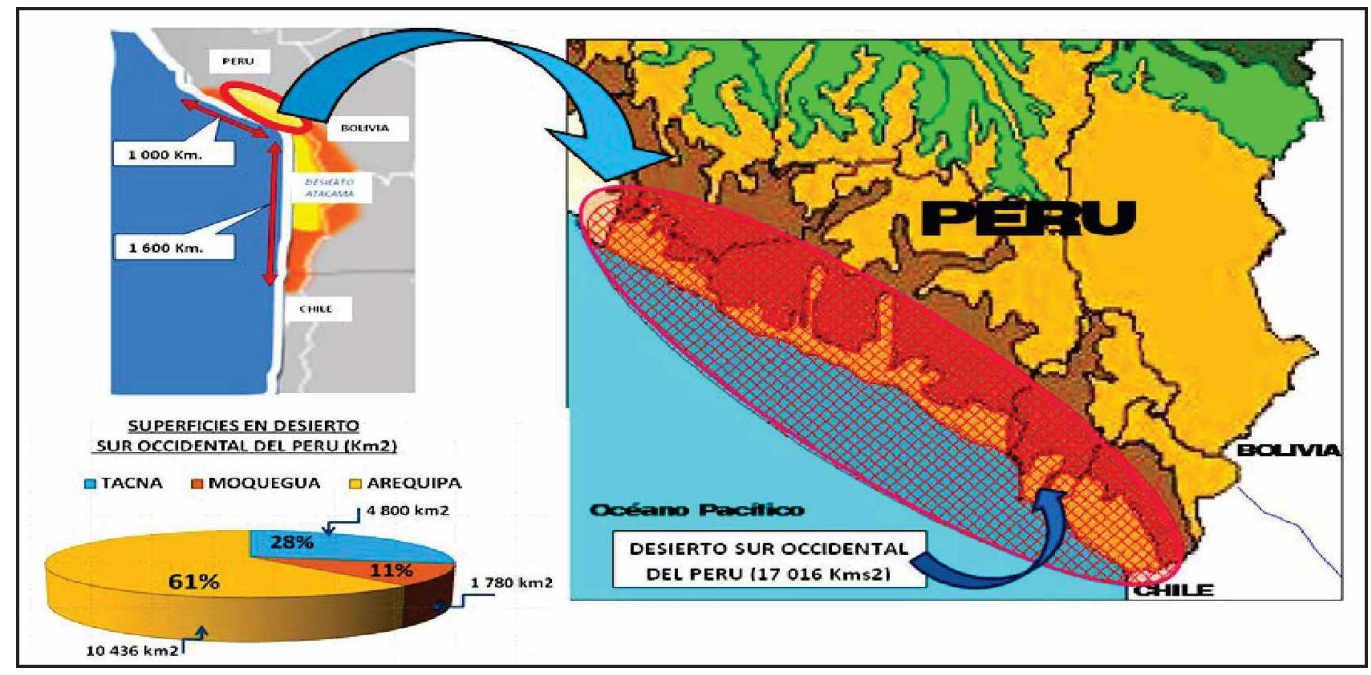

Figura 2. El desierto sur occidental penuano, inscrito en el desierto de Atacama Fuente: Google Earth

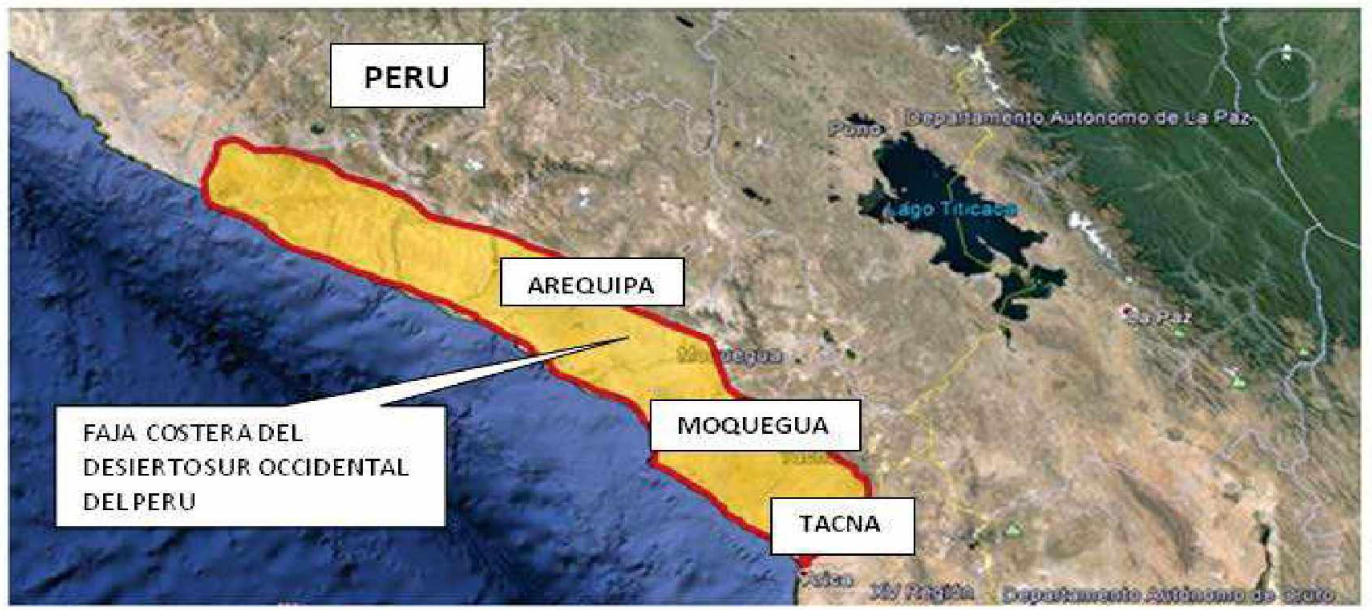

Figura 3. El desierto sur occidental peruano, inscrito en el desierto de Atacama Fuente: Google Earth

Es la costa el escenario de la problemática expuesta. Esta región en los últimos 50 años, por el intenso proceso en migraciones de zonas rurales hacia las urbanas, ha soportado el mayor crecimiento poblacional (Zegarra, 2004); verificando ello, se puede percibir que la ciudad emplazada plenamente en la costa desértica sur del Perú, como es Tacna, ha soportado desde el año 1970 una fuerte migración, generando grandes conos marginales adyacentes al área urbana consolidada.

El estado peruano a finales del siglo pasado, creó el Programa de pequeñas y medianas irrigaciones, a través del Ministerio de Agricultura, y en 1970, dio inicio al Proyecto Especial Majes Siguas, realizando grandes inversiones dirigidas a irrigar las zonas del desierto costero. Parte de estas inversiones fueron 
asignadas al sector agricultura, y tenían la factibilidad de captar aguas de los ríos de las cuencas costeñas, que van desde el río Acarí en la provincia de Caravelí (Arequipa) hasta el río Caplina (Tacna), o en otros casos, captan aguas de la cuenca del Atlántico, como es el caso Proyecto Majes.

La escasa disponibilidad del recurso agua es un reto para un desarrollo sostenible de la costa peruana. Hatta y otros (Zegarra, 2004) exponen que en el caso de la agricultura costeña, sólo un $30 \%$ de las aguas captadas por lluvias, tiene el uso efectivo, perdiéndose el resto en el Océano Pacífico o por filtraciones.

Del contexto espacial, se determina la síntesis de los tipos de asentamientos emplazados en la faja costera sur entre las regiones de Arequipa y Tacna, y son:

- Por grado de ocupación

Asentamientos formales: Centros poblados emplazados con planificación previa del territorio y que cuentan con el saneamiento legal (centros poblados en irrigaciones, otros).

Asentamientos informales: Ubicados como producto de una invasión y ocupación ilegal del territorio desértico y sin planificación previa y sin saneamiento legal (caseríos periféricos a centros poblados formalizados, usos pre urbanos, otros)

- Por tipos de usos de suelo

Asentamientos urbanos: Con infraestructura vial y de saneamiento, radicación consolidada residencial concentrada, con más de 5000 habitantes, y servicios básicos (centros poblados en el Proyecto Majes).

Asentamientos rurales: Con saneamiento básico, de carácter disperso, servicios comunales, con más de 2000 habitantes (centros irrigacionales de Arequipa).
Asentamientos irrigacionales: Sin saneamiento básico, con predominancia de áreas agrícolas y caseríos dispersos (pequeñas y medianas irrigaciones en Arequipa y Tacna).

Asentamientos pre urbano rurales: Son periféricos y adyacentes a las vías, panamericana sur, vías sub regionales, sin saneamientos básico ni técnico legal, y con caseríos dispersos, y producto de una ocupación ilegal para usos pecuarios y pre urbanos (granjas, servicios al transporte, otros informales).

\section{Contexto social}

Las ocupaciones de los espacios disponibles en el mundo, con fines de asentamientos humanos, muchas veces se producen con violencia o acciones forzadas estos espacios desérticos cercanos a centros urbanos, siendo el caso del Perú, uno de los países donde se exponen las motivaciones sociales más significativas al ocupar territorios del estado, y en algunos casos privados; como evidencias tenemos los territorios tomados de Villa El Salvador y la zona de Pamplona en Lima, en las últimas dos décadas del siglo pasado, con las ocupaciones informales en el cono norte (Arequipa), sector norte al CP El Pedregal (Proyecto Majes) o los asentamientos en las áreas aledañas a la irrigación San Camilo (Arequipa), y en la zonas desérticas de la frontera con Chile de la Quebrada Hospicio y las pampas de Sama en Tacna, como se ejemplifica en la figura 4.

Justificadas o no las razones de ocupación, el resultante eco ambiental está ahí, a la vista de todos, y el espacio se consume para transitar, intercambiar y comercializar o para una simple expectación visual del espacio natural que nos ofrece este bondadoso ecosistema. La informalidad e ilegalidad de estas imprevistas ocupaciones del espacio se ha convertido en tema inmanejable y complejo, y en otros casos será difícil recuperar ecosistemas perdidos.

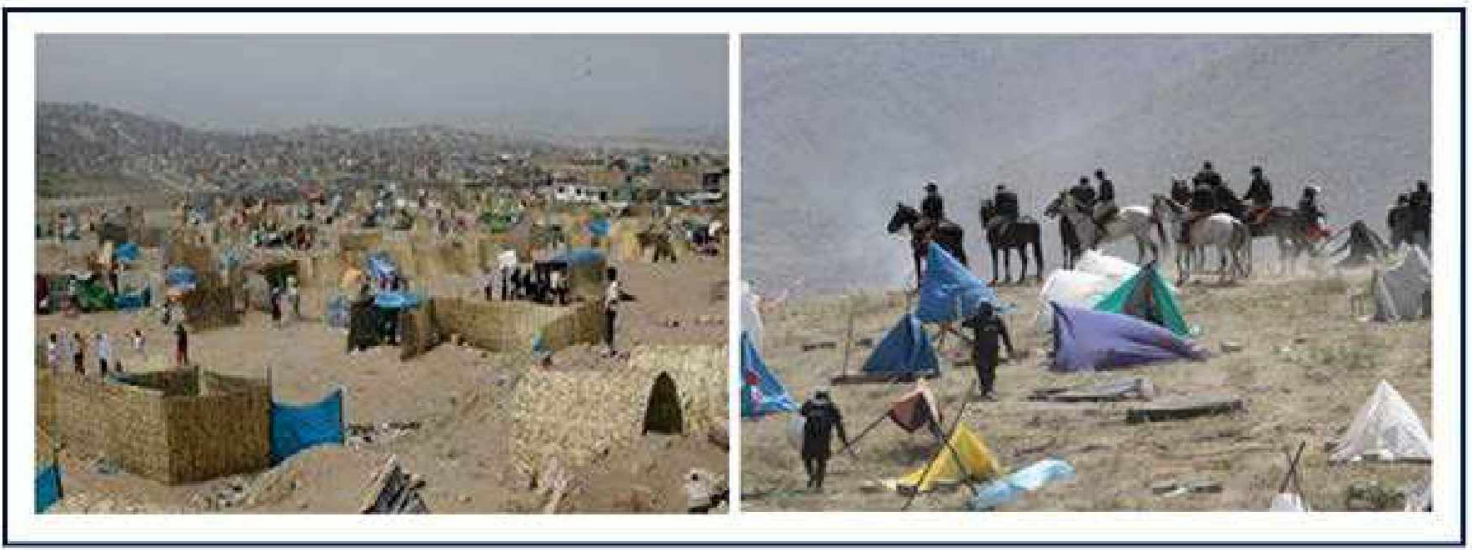

Figura 4. Invasiones en el cono sur de Lima Fuente: Google 


\section{Contexto medio ambiental}

El Perú es un país con un territorio tropical a pesar de tener una gran diversidad y condiciones climáticas variadas que van desde altas temperaturas $y$ extremadamente frías, con una de las geografias más caprichosas y agrestes del mundo; ello, le otorga un privilegio medio ambiental, por su biodiversidad, variedad y suelos; estos pisos ecológicos fueron estudiados por científicos. El Perú se divide en ocho regiones naturales, cuyos denominación y nomenclatura quedan definidos en la toponimia regional peruana como: Chala, Yunga, Quechua, Suni, Puna, Janca, Rupa-Rupa y Omagua (Pulgar, 2014). Esta estructura definida en sentido transversal según su elevación topográfica (figura 5), ha marcado la base de nomenclatura de las regiones naturales y las eco zonas que otros estudiosos las ratificaron, siendo el desierto, una de estas eco zonas, destacando para el estudio las regiones Chala que va desde los 0 a 500 m.s.n.m. y Yunga que va desde los 500 a 2300 m.s.n.m, en estas estribaciones de la cordillera occidental andina $y$ de la costa, la imagen geomorfológica se da con ligeras depresiones o sobre elevaciones, con valles relativamente profundos $y$ ríos que van hacia la cuenca del Pacífico, posibilitando captar aguas para irrigar tierras desde Arequipa hasta Tacna.

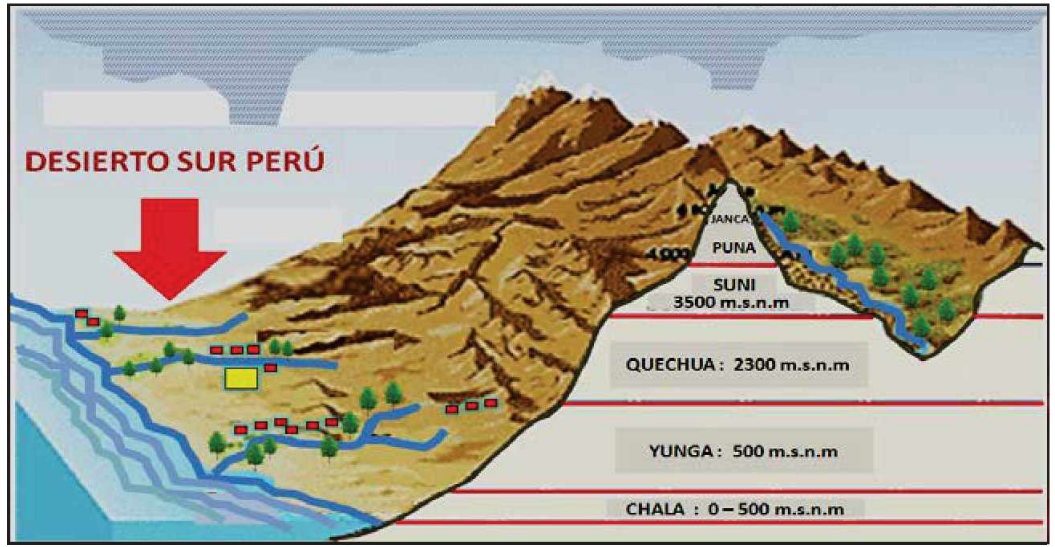

Figura 5. El desierto dentro de las ocho regiones naturales del Perú Chala Fuente: Pulgar-Vidal (1981)

En los procesos eco territoriales intervienen los escenarios ambientales del ecosistema desértico sur, que cuenta con un clima subtropical, con escasa vegetación por la falta de agua, con mucha humedad invernal, con gran capacidad agrológica en lo agrícola $y$ forestal, que de forma longitudinal muestra una franja estrecha surcada por valles agrícolas y de centros poblados tradicionales; los componentes escénicos y de paisaje, se resumen a nivel de las planicies, dunas de arena y pampas desérticas y a diferencia del borde oriental hacia los andes, el borde occidental se expresa en acantilados y fajas de playas de arena y protuberancias rocosas en menos porcentaje. Esta expresión geomorfológica del ecosistema y sus atributos paisajísticos ofrecen condiciones para actividades relativamente nuevas en el desierto, entre ellas, los deportes de aventura y competencias como el Dakar, estudios de cinematografia y fotografía (figura 6).

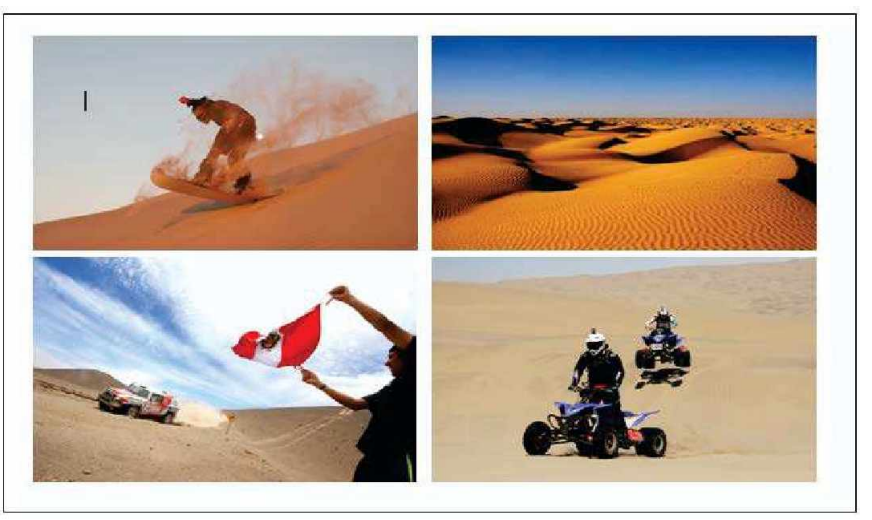

Figura 6. El desierto dentro de las regiones naturales Chala y Yunga Fuente: Pulgar-Vidal (1938) 
En cuanto a la flora se tiene predominancia de gramas y tilansiales y estacionalmente en invierno afloran las lomas silvestres por la lluvia invernal; referente a la fauna, en el desierto predominan los insectos, lagartijas, aves silvestres, pequeños saurios entre otros.

Este espacio en términos medio ambientales es potencialmente sensible. Los impactos pueden ser negativos y de daños irreversibles a los ecosistemas y patrimonio (Becerra, 2010); el uso informal, especialmente de las áreas ocupadas sin el saneamiento fisico legal, impacta negativamente en el paisaje del desierto y genera la pérdida del valor agrológico del suelo. El medio visual es parte de la vida de los habitantes (Lynch, 1974), pero el escenario desértico, ha sido impactado negativamente en su contexto visual.

\section{Los procesos eco territoriales}

Los grados y procesos eco territoriales tienen múltiples implicancias que van desde la búsqueda de empleo, estabilidad de radicación, hasta el tráfico de tierras y captura abrupta del territorio. Los procesos se dividen en:

\section{Procesos formalizados}

Los proyectos irrigacionales dan una referencia formalizada del grado de ocupación y emplazamientos de los asentamientos dentro del área del desierto costero sur occidental, que desde 1930 aproximadamente se empezó a colonizar el desierto costero de Arequipa con la irrigaciones de la Joya Antigua (Vítor, Arequipa) y Santa Rita de Siguas y luego en la década del 70, se implementa el Programa de pequeñas y medianas irrigaciones del Ministerio de Agricultura (Línea global) durante el gobierno de facto, que planificó irrigaciones en el espacio desértico de Arequipa, como San Isidro, San Camilo y La Cano que representan un buen ejemplo de explotación sostenible de suelos en el desierto y con emplazamientos equilibrados (tabla 1).

Tabla 1. Contexto temporal de los componentes de ocupación del territorio costero sur en el tiempo

\begin{tabular}{|c|c|c|c|c|}
\hline \multirow{2}{*}{$\begin{array}{l}\text { ECOSISTEMA } \\
\text { COSTERO SUR }\end{array}$} & \multirow[b]{2}{*}{ ANTES A 1950} & \multicolumn{3}{|c|}{ PERIODOS DEL CONTEXTO ESPACIO TIEMPO DEL ESTUDIO } \\
\hline & & $1950-1968$ & $1968 \cdot 1980$ & $1980 \cdot 2000$ \\
\hline $\begin{array}{c}\text { GRADO DE } \\
\text { OCUPACIÓN EN } \\
\text { ESPACIO DESIERTO }\end{array}$ & $\begin{array}{c}\text { WALLES Y CENTROS } \\
\text { POBLALOS COSTEÑOS } \\
\text { TRADICIONALES PRE } \\
\text { EXISTENTES / IRPIGACIONES } \\
\text { LA JOYA NUEWA Y SANTA } \\
\text { RITA DESIGUAS }\end{array}$ & $\begin{array}{l}\text { NUEVOS CENTROS } \\
\text { POBLADOS, } \\
\text { CONSOLIDACIÓN DE } \\
\text { CARRETEFA } \\
\text { PANAMIMERICANA/ } \\
\text { IRRIGACIONES EN } \\
\text { PRODLLCIÓN } \\
\text { AGROPECLUARIA [SANTA } \\
\text { RITA/ LA JOYA ANTIGUA] }\end{array}$ & $\begin{array}{l}\text { PROYECTOSY OBRAS EN } \\
\text { PEQUEÑAS Y MIEDIANAS } \\
\text { IRRIGAGIONES, Y } \\
\text { ASENTAMIENTOS } \\
\text { POBLACIONNALES EN } \\
\text { CENTROS DE SERVICIO/ } \\
\text { INICIO DEL PROYECTO } \\
\text { MAJES / SE INICIAN } \\
\text { INTENSIVAMENTE } \\
\text { OCUPACIONES INFORMALES } \\
\text { ENZONAS ERIAZAS }\end{array}$ & 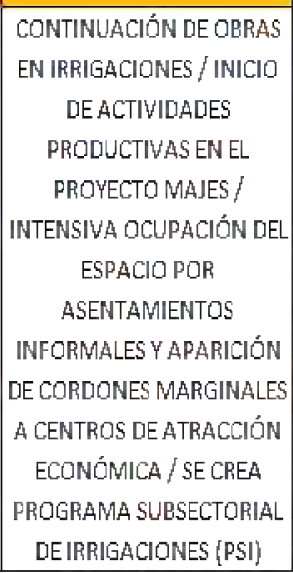 \\
\hline
\end{tabular}

Fuente: Elaboración propia

En la región Tacna, el Proyecto de Riego Tecnificado PROTER, en el faja costera, representa un ejemplo de exposición de cultivos en el escenario del desierto, así como las zonas tradicionales irrigaciones de Magollo y La Yarada, que son la gran despensa olivar del Perú. Adicionalmente, en el espacio del desierto sur occidental, se han presentado petitorios mineros y con fines agrícolas, como Irrigación Ocoña en zonas de desierto costero en Ocoña, (Camaná, Arequipa) de carácter privado, igual que la Irrigación Pampas de la Clemesí (Moquegua).
Esta expresión de ocupación espacial de los territorios desérticos del sur de Perú, han cumplido formalmente desde la planeación hasta la construcción y producción agropecuaria en las décadas del 60 y 70, representaron para Arequipa, importante despensa agro alimentaria y de excelente productividad agrícola. La muestra espacial se denota en el centro desértico de Arequipa (figura 7). 


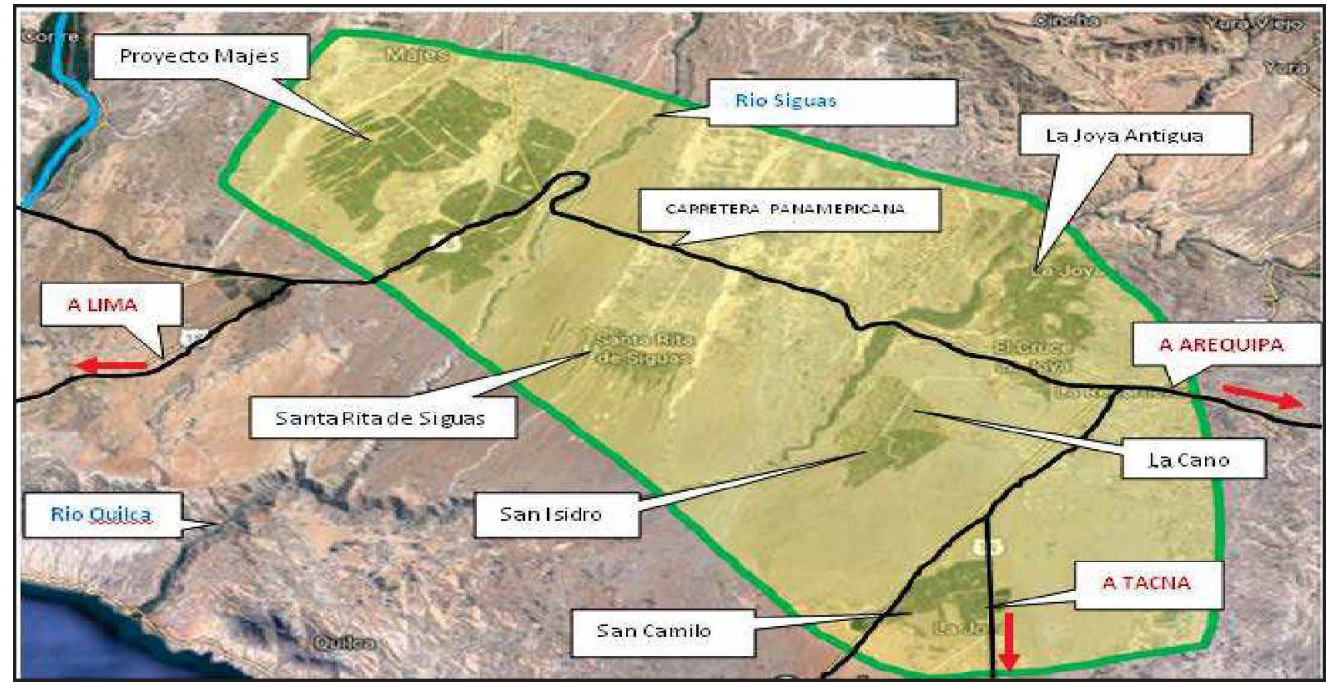

Figura 7. Emplazamiento eco territorial en la zona de desierto centro de Arequipa de proyectos irrigacionales Fuente: Google

Un caso especial es la ocupación formalizada del Proyecto Majes, que en su concepto original y su proyección a irrigar cerca de 60000 hectáreas, a la fecha tiene en explotación 16000 ha, representando una importante oferta alimentaria para el mercado regional y nacional. El Proyecto Especial Majes Siguas, según D.L No 18375 del 21de agosto de 1970, declara de necesidad y utilidad pública la ejecución del proyecto Majes, con el inicio de las obras en octubre de 1971. Según un documento informativo del Gobierno Regional de Arequipa (2016), este se concibe como un proyecto de impacto regional integral dirigido sobre todo al desarrollo agrícola y energético, desde su creación por el gobierno militar, representa una importante oferta de alimentos para la región de Arequipa y el país, a la fecha representa una inversión de \$2 474 millones.

La creación de la Autoridad Autónoma de Majes (AUTODEMA) creada según Ley $\mathrm{N}^{\circ} 23350$ de 1982, significó un ejemplo institucional de cómo se puede operar y conducir emplazamientos espaciales de los asentamientos humanos en los Centros de Servicio que se dieron en las secciones $\mathrm{A}$, con los Centros Poblados (CP), El Pedregal, El Alto y La Colina, y con Centros de Servicios Básicos en las secciones B (04), C (03), D (05) y E (08), según los procesos de ocupación se configuró, tal como se puede apreciar en la figura 8.

- Los CP descritos en la sección A, planteaban parcelas urbano rurales equidistantes a cierto número de tierras, que en promedio de 700 hectáreas eran servidas por un CP., donde se planteaba que el colono y su familia trabajen en sus parcelas por el día y se trasladen a la zona de residencia en los CP donde se emplazaban los equipamientos y servicios comunales, y la residencia permanente del colono y su familia; pero, este modelo en realidad no funcionó, porque las distancias de las zonas de parcelas en muchos casos eran muy distantes al CP., generaba costos en transporte y dificultad en los desplazamientos por la falta de infraestructura vial; por ello, el colono fijó residencias permanentes dentro de la parcela generándose un modelo espontáneo de ocupación en los asentamientos y los usos del suelo en los $\mathrm{CP}$., se intensificó el uso comercial y de servicios, posteriormente, se convirtieron en usos residenciales, con alto valor del suelo urbano en los CP.

Según el INEI, en la década del 90, se llegó a tener la tasa de crecimiento más alta del Perú con un $16 \%$ respecto a la tasa promedio nacional del $2,3 \%$, convirtiéndose estos centros poblados y los entornos productivos, en centros atractivos para la migración poblacional hacia el proyecto siendo el CP. El Pedregal, el de mayor crecimiento intensivo en la década del 90. Como instrumentos de planificación, estos CP., se desarrollaron bajo la referencia normativa del DS. 007-85-VC, que aprobó el Reglamento de Acondicionamiento Territorial, Desarrollo Urbano y Medio Ambiente que posibilitó los Planes Ordenamiento Urbano para El Pedregal en el Proyecto Majes, aunque con tratamiento especial por ser un proyecto irrigacional. 
Luego de esta experiencia de emplazamientos eco territoriales dentro de un espacio, que hasta inicios de 1980 era vacío, se reformuló el modelo y se continuó con la incorporación de tierras sobre el desierto al tener el recurso hídrico disponible, ampliándose las secciones A, B, C, D y E con un total de 20 centros de servicios básicos, donde se plantea un emplazamiento modular de 500 hectáreas, asignándose las adjudicaciones por colono y su familia parcelas de 5,5 hectáreas, que posibilitaba una parcela neta agrícola de 5,0 ha y un cortijo de $500 \mathrm{~m}^{2}$, que representa un recinto múltiple que contiene la residencia del colono y familia, zonas de servicio agropecuario, zona de crianza de animales menores y en casos corral de animales mayores.

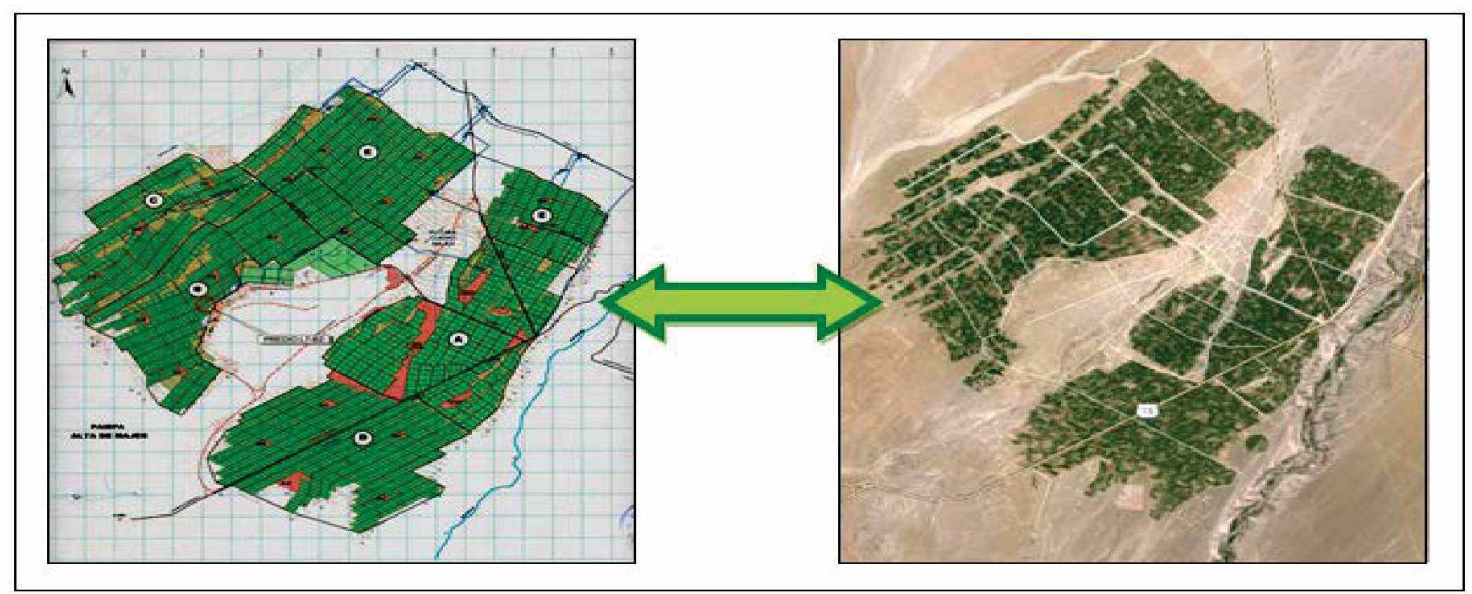

Figura 8. Proyecto Majes: Comparación entre lo planificado y la realidad resultante en el desierto Fuente: AUTODEMA / Google Earth

Este proceso representó en el año 2000 para el Proyecto Majes, las siguientes resultantes estadísticas en cuanto a indicadores en el grado de consolidación del proyecto en general y el desagregado por sector urbano, que deberían responder a los objetivos y metas del Proyecto Majes (figura 9).

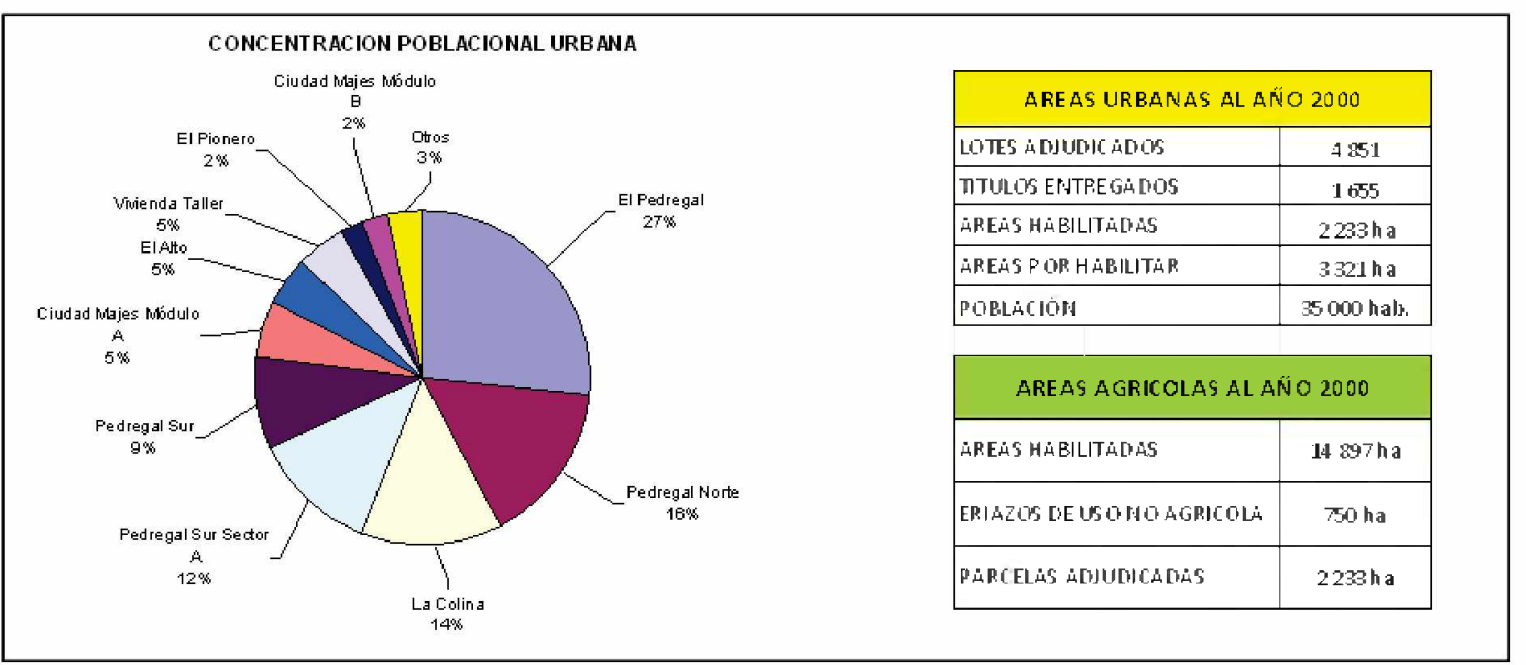

Figura 9. Proyecto Majes, distribución poblacional y grados de ocupación resultante al año 2000 Fuente: AUTODEMA

- En cuanto a los instrumentos legales, estos asentamientos y parcelas agrícolas, se formaron tomando referencias del DS. 007-85-VC, que era competencia de aplicación de los gobiernos locales, pero en el año 1989, se da el DS. 050-89-MIPRE que aprueba el Reglamento de Adjudicación de Tierras con fines agrícolas, urbanos, otros usos y de cesión en uso del Proyecto Majes-Siguas; esto generó, posteriormente, observación por los gobiernos locales que argumentaban que por la Ley Orgánica de Municipalidades y la Constitución Política, era competencia de los gobiernos locales regular el planeamiento de los centros urbanos y de otros usos dentro de la expansión urbana y esta controversia de agudizó en el año 1999 cuando se crea el distrito de Majes según Ley $\mathrm{N}^{\circ} 27236$, y se trasladan competencias de AUTODEMA, a dicha municipalidad. 


\section{Procesos no formalizados}

Esta tipología representa a los asentamientos que en el tiempo han ocupado y ocupan los espacios adyacentes a las vías panamericana sur, binacional, sub regionales, y a centros de producción y de servicios de atracción económica y de intercambio, sin el saneamiento físico legal del caso, al haber ocupado el territorio mediante un proceso sistemático o abrupto con conglomerados sociales que migraron a dichos espacios, representando a la fecha procesos de recurrencia administrativa y legal en pos de la formalización.

\section{RESULTADOS}

\section{Procesos de emplazamiento}

Como primer ámbito de análisis, se toma el Proyecto de irrigaciones en el desierto central de la región Arequipa, a cargo del Ministerio de Agricultura y sus dependencias sectoriales como Línea Global, que formulaba los emplazamientos con prioridad en lo agrícola y en la distribución de la infraestructura de riego, lo mismo que con las irrigaciones tradicionales de Santa Rita de Siguas y La Joya Antigua (Vítor), en la década del 60 al 70, se instalaron en las pampas desérticas de La Joya en la Región Arequipa; estos dos ámbitos muestra son: La Cano y San Camilo, que pertenecían al Programa de pequeñas y medianas irrigaciones del Ministerio de Agricultura, cuya captación de agua provenía del río Chile, llegando mediante canales a irrigar dichos terrenos desérticos.
Estos asentamientos, prioritariamente rurales, eran Centros Poblados de Servicios Básicos, con usos de comercio local, educación y salud sobre todo, además de la residencia, y adicionalmente tenían un cortijo y residencia temporal en la parcela de producción tornándose luego en definitiva. Ahora, se observa que en dicho periodo temporal, estos asentamientos fueron destinos de migraciones desde los centros urbanos mayores de la región Arequipa, como no fueron planificados en su crecimiento y expansión urbana, se originaron asentamientos marginales desorganizados, con consecuencias medio ambientales negativos en cuanto a saneamiento y tratamiento de desechos urbano rurales.

En el análisis, se exponen dos casos que muestran las consecuencias en los procesos de planeamiento y de gestión preventiva que se anticipó a lo que hoy se observa. El primer caso se refiere a las irrigaciones de La Cano y San Camilo, expresiones de la ampliación de la frontera agrícola de la década del 60 y 70 , donde se observa una importante ocupación del territorio por asentamientos no formalizados en los perímetros a parcelas agrícolas y centros urbano rurales de servicios básicos y adyacentes a vías como la carretera panamericana sur en San Camilo, o a centros poblados y canales de riego matriz como en La Cano (figuras 10 y 11).

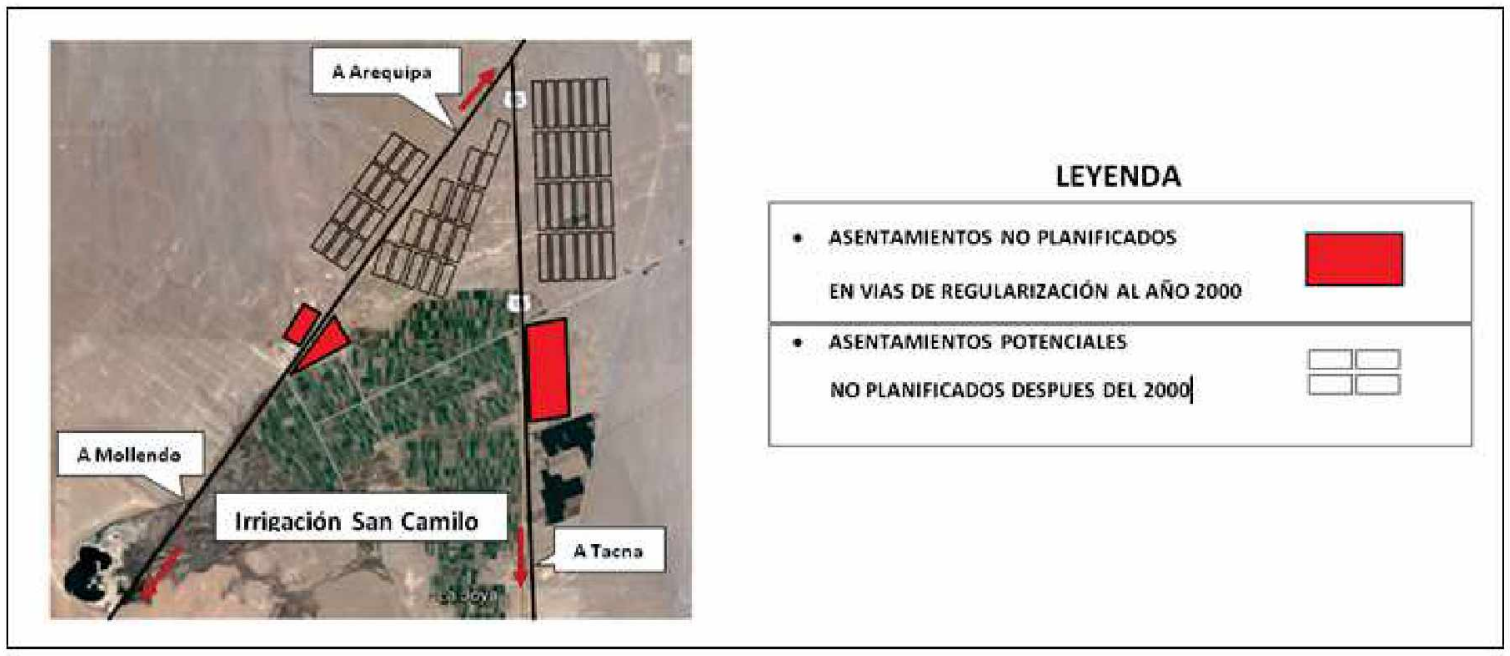

Figura 10. Caso San Camilo: Asentamientos Periféricos no planificados al 2000

Fuente: Google 


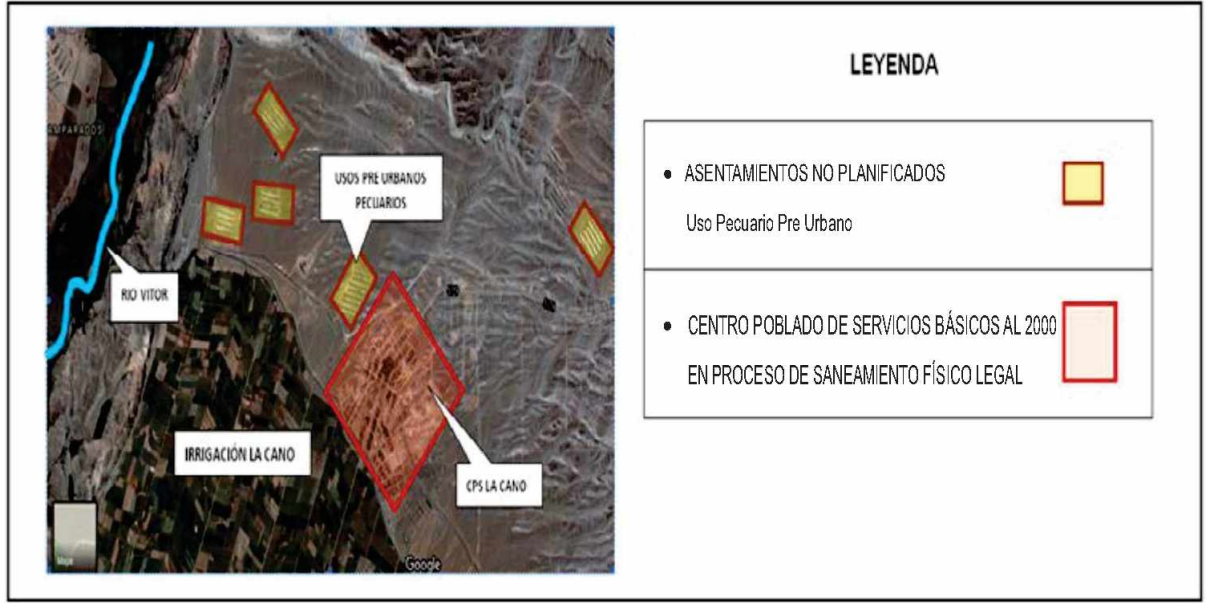

Figura 11. Caso La Cano: Asentamientos Periféricos no planificados al 2000

Fuente: Google

Como segundo caso, se expone el emplazamiento del Proyecto Majes, ubicado en el territorio desértico de las Pampas de Majes, que con las aguas trasvasadas del río Colca al río Siguas, se inicia el proceso de colonización en la década del 80 . En 1983, se inicia la adjudicación de parcelas en la Sección A con los Centros Poblados indicados, es decir La Colina, El Alto y El Pedregal, que ocupaban aproximadamente 2500 ha, donde los procesos de ocupación eco territoriales obedecían a un modelo de asentamiento concentrado y que se propuso para los primeros asentamientos en 1983 por la AUTODEMA, que se fundamentaba en el diseño de módulo agro urbano conformado por un Centro Poblado con los servicios básicos y lotes para residencia permanentemente de 500 colonos aproximadamente, que tendrían sus parcelas en el entorno periférico al centro, como se expresa en la figura 12; pero, este modelo generó que la mayor parte de los colonos tengan excesivos desplazamientos entre sus parcelas y el centro poblado donde se les asignó la residencia familiar.

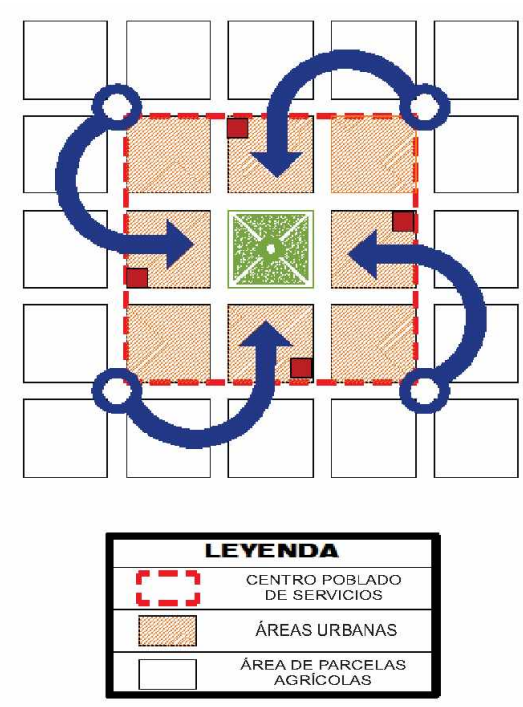

Figura 12. Primera etapa de asentamientos en la sección A del Proyecto Majes (1983). Modelo Concentrado Fuente: Elaboración propia

Luego de los problemas de accesibilidad, inversión de tiempo, desatención familiar, por los desplazamientos indicados y que tenían frecuencia diaria de ir desde las parcelas -que en casos distaban a un kilómetro de la residencia del colonomuchos colonos, sobre todo los que tenían parcelas más alejadas del centro poblado, optaron prácticamente por sub utilizar la vivienda ubicada en dicho poblado y acondicionaron sus viviendas dentro de la parcela, generándose el segundo modelo, y que se da en la actualidad y como variante del formulado en 1983 por la AUTODEMA, es decir con una estructura desconcentrada, como expresión de una necesidad real de que el colono esté más cerca de su parcela, aun, cuando esté lejos de los servicios comunales (figura 13). 


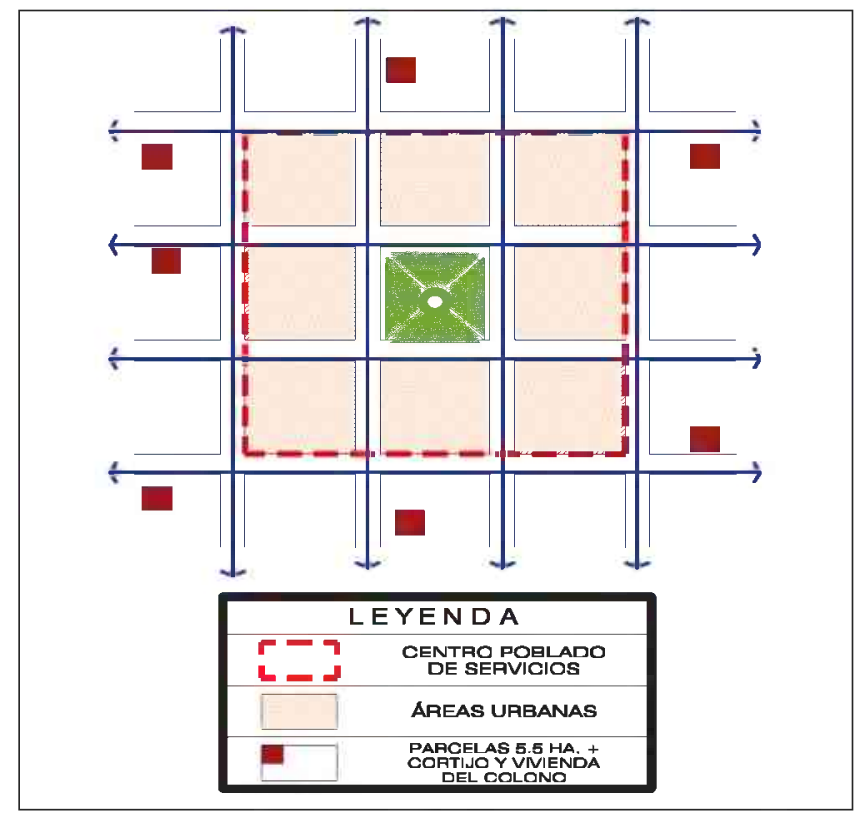

Figura 13. Asentamientos en la sección A del Proyecto Majes (Posterior a 1983). Modelo desconcentrado Fuente: Elaboración propia

Posteriormente, tras las experiencias de los modelos anteriores y para mejorar los procesos de producción, la vida familiar de los colonos, optimizó los flujos de bienes y servicios, dando un mejor uso del suelo desértico, con un equilibrio y relativa equidistancia entre las zonas servidas y zonas servicio. Este modelo mejoró los niveles de productividad agropecuaria del proyecto, las inversiones de infraestructura se racionalizaron, en razón, que las vías articulaban las parcelas que tenían 5,5 ha para uso agrícola, el cortijo y su vivienda, se convirtieron en módulos semi desconcentrados de un centro poblado, sea este de servicios o de servicios básicos (figura 14).

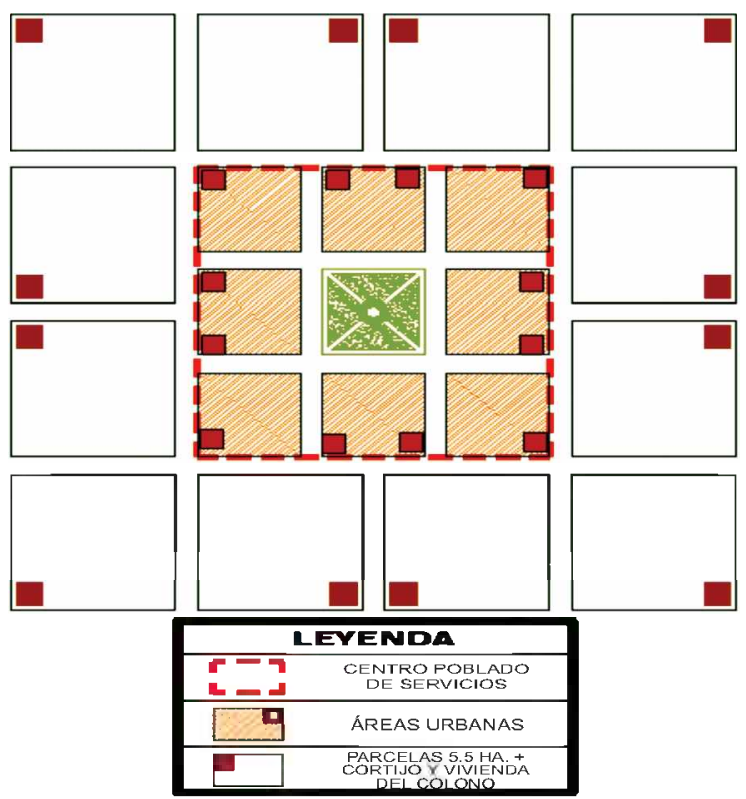

Figura 14. Modelo semi desconcentrado de las actuales secciones B, C, D y E del Proyecto Majes Fuente: Elaboración propia

Pero esta dinámica y los flujos migratorios intensivos hacia dicho proyecto, originó un emplazamiento marginal y/o periférico en los contornos de los centros poblados principales como El Pedregal que al año 2000, llegó a tener unos 30000 habitantes aproximadamente, y con serios problemas medio ambientales y de saneamiento como la calidad del agua para consumo humano. Estos emplazamientos no formalizados, representaban como los ejemplos típicos anteriores, una captura del territorio circundante, motivada por la presencia de centros de atracción laboral y económica, representando para la 
AUTODEMA los gastos en acciones legales de desalojo.

\section{DISCUSIÓN}

El tema analizado en sus tipologías expuestas posibilita contrastar las actuaciones en la ocupación del territorio del desierto sur occidental del Perú, que para el caso de los más significativos como: la ocupación por la agricultura y los asentamientos humanos, identificando los instrumentos de planificación en dos niveles:

\section{Nivel formalizado:}

En los emplazamientos formalizados, donde el estado y las instituciones públicas diseñaron previamente las localizaciones de los asentamientos humanos, la Oficina Nacional de Planeamiento Urbano (ONPU) normaba a partir de los Planes Reguladores que fueron modificados en sus competencias, por el gobierno militar después de 1968, con el Plan Nacional de Desarrollo Urbano 1975-1990 (PNDU), el Sistema Nacional de Equipamiento (SISNE), asignaba a los planes urbanos los códigos, nomenclaturas y los rangos, funciones, rol y jerarquía de los asentamientos dentro del Sistema Nacional Urbano.

El anexo del Título Primero denominado "Condiciones Básicas de Habitabilidad. Organización Física del Asentamiento", se establecen normas tanto para la localización como para la organización física del asentamiento (Castro-Pozo, 2006) y sólo después de la dación de la Ley Orgánica de Municipalidades $\mathrm{N}^{\circ} 23853$ y el Decreto Supremo $\mathrm{N}^{\circ}$ 053-84-VC, que aprueba el Reglamento de saneamiento físico legal de los Asentamientos Humanos dando competencias a las municipalidades provinciales para dicho saneamiento, que en el caso de Arequipa, se regularizó los asentamientos de El Triunfo y El Cruce de La Joya, con la correspondiente titulación.

El DS. $N^{\circ}$ 007-85-VC, que aprobó el Reglamento del Acondicionamiento Territorial, Desarrollo Urbano y Medio Ambiente dado en el segundo gobierno de Fernando Belaúnde Terry, dentro de los Planes Urbanos contenía tres tipos: Plan de Desarrollo Metropolitano, Plan Director y Plan de Ordenamiento, este último sirvió de referencia para planificar y sanear los Centros Poblados de El Pedregal, La Colina y el Alto en el Proyecto Majes, otros asentamientos en La Joya y San Camilo en Arequipa y los asentamientos de La Yarada y Magollo en Tacna. En 1989, se emite el DS $\mathrm{N}^{\circ} 050-$ 89-MIPRE, que permite formalizar las habilitaciones urbanas del Proyecto Majes ante la Municipalidad de Caylloma (Arequipa) por parte de AUTODEMA.
Nivel no formalizado:

La atracción de los centros agropecuarios, la accesibilidad a la carretera panamericana sur, las expectativas de futuras ampliaciones de la frontera agrícola con proyectos privados y de explotación minera, conllevó a que los asentamientos formalizados, opten por la captura del territorio mediante la modalidad de posesión por invasión, el estado, los sectores ministeriales y las municipalidades no consiguieron aplicar el control urbano rural, llegando en algunos casos a desalojos violentos de las áreas ocupadas y la demolición de infraestructuras hechas informalmente.

Mediante la emisión del Decreto Supremo $N^{\circ} 053-$ 84-VC, se regularizó los petitorios de adjudicación, de posesionarios ilegales, formalización urbanística, ocupaciones de los asentamientos informales, como consecuencia, en muchos casos, del tráfico de tierras con masas sociales expectantes sin considerar criterios ambientales, económicos, socioculturales, institucionales y geopolíticos, que no necesariamente consideraban un mínimo nivel de habitabilidad. El ordenamiento territorial posibilita que las personas logren un desarrollo integral y una garantía en su calidad de vida (Azpur, 2012).

Los procesos de intensa ocupación informal, que han tenido los centros productivos en los asentamientos agropecuarios de la región, no han dado un resultado ambiental y territorial satisfactorio. Lo extensivo de la explotación y la presencia espacial de un gran centro exportador comercial y administrativo, crean a la vez, condiciones para un crecimiento urbano concentrado, en torno a este centro principal (Castells, 1973). Asimismo, estos asentamientos no cuentan con los servicios básicos de saneamiento, las construcciones son precarios recintos sin permanencia residencial, con gran cantidad de desechos urbanos en los entornos; igualmente encontramos, canteras ilegales, granjas instaladas en espacios muchas veces no aptos y sin estudios de impactos ambiental, centros de servicios de transporte sin las instalaciones necesarias, entre otros.

Un protagonismo en los grados de ocupación eco territorial a nivel formalizado, han tenido las irrigaciones con fines agropecuarios, en razón del valor agrológico y medio ambiental, paisajista del espacio desértico sur; por la observación de sus dimensiones, el modelo disperso o semi concentrado de los centros de servicios rurales, es una buena opción modular y ha definido los siguientes tipos de ocupación:

Formales: Proyectos irrigacionales, carreteras, líneas férreas, agroindustrias, centros poblados tradicionales y nuevos, campamentos militares, centros de recreación de aventura, centros agropecuarios y pecuarios autorizados.

No formales: Invasiones poblacionales, Asentamientos Informales (AI) direccionados hacia 
Centros Atractores (AC) que motivan demanda de mano de obra cercana a los mismos, como se teoriza el modelo espacial (figura 15) y que por su emplazamiento estratégico, está generando potenciales oportunidades para los intercambios y generación de empleo.
La expresión espacial indicada, nos muestra la abstracción de un modelo que describe una situación actual. Estos modelos posibilitan entender las implicancias en la exposición de las estructuras de ciudades y regiones (Acuña, 2000).

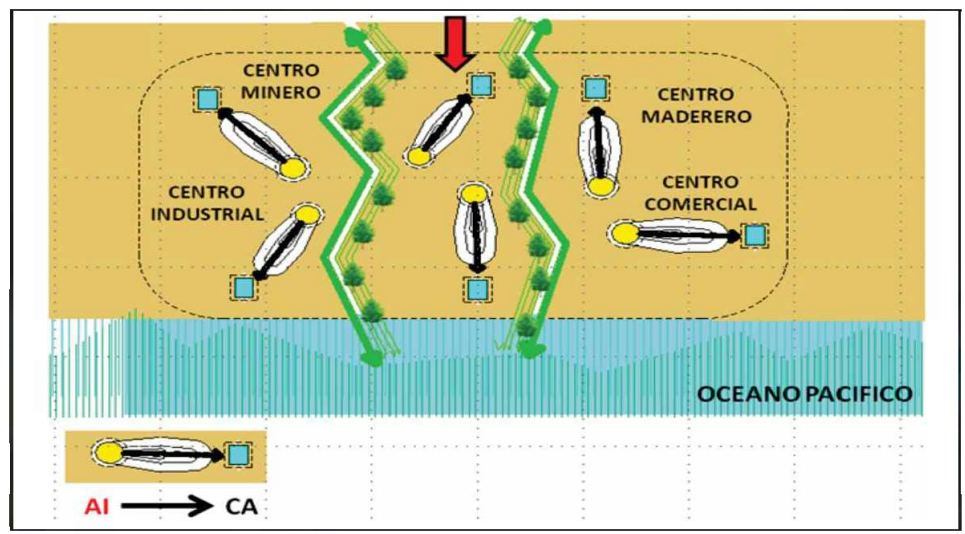

Figura 15. Modelo Asentamientos Informales (AI) direccionados a los Centros Atractores (CA) Fuente: Elaboración propia

Igualmente, se observa la consolidación de los corredores eco productivos y de intercambio en la Macro Región Sur, como la carretera interoceánica, polo petroquímico, eje ferroviario binacional, gaseoducto sur, entre otros, que tendrán en el desierto costero sur del Perú, un espacio de reserva para las grandes inversiones. En el enfoque de estos cambios, en la tradición geográfica de campo y ciudad, con la que fuimos educados y poder expresarlos, no es necesario ampliar mucho nuestro vocabulario (Geddes, 1960); esto motivará ocupaciones planificadas y no planificadas en el espacio territorial, y la consiguiente pérdida eco sistémica y del paisaje, proyectándose una peligrosa "Urbanización del Desierto" (figura16).

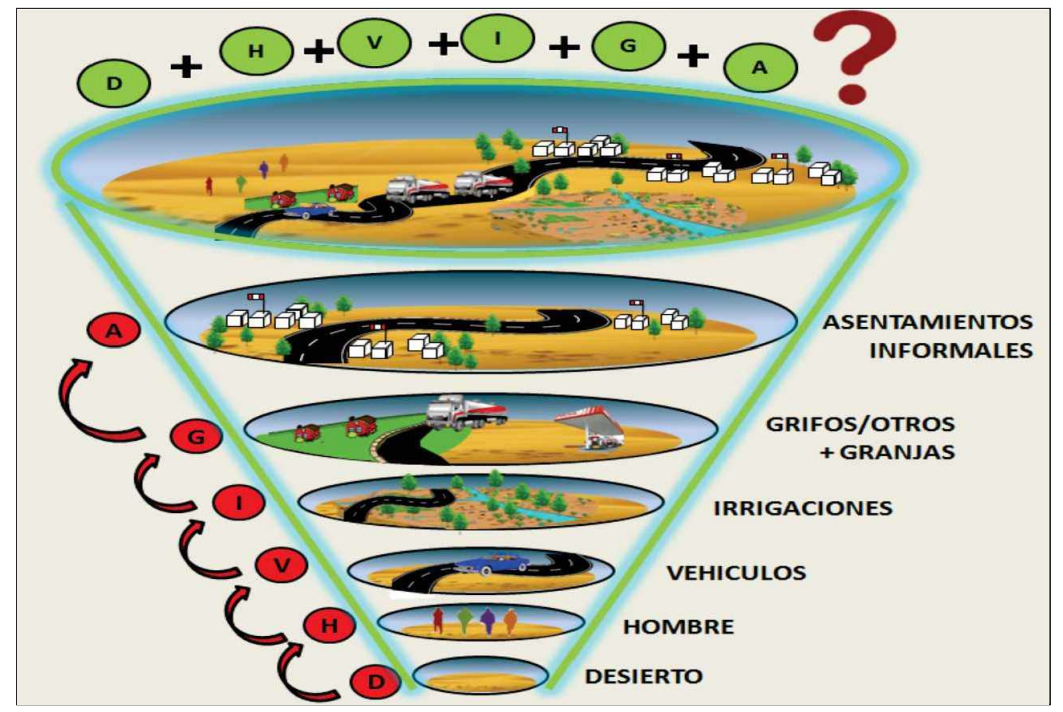

Figura 16. Evolución de la ocupación espacial en el desierto costero sur peruano Fuente: Elaboración propia

\section{CONCLUSIONES}

En este aspecto, se tiene que identificar que dentro de las ocupaciones del desierto en los años y décadas pasadas, los emplazamientos informales son los que han predominado en este ecosistema y son las causas principales de su deterioro ambiental y paisajístico, esto se funda en la motivación de ocupación territorial por conglomerados sociales guiados por liderazgos engañosos que alientan la ocupación del desierto. E1 asunto del saneamiento físico-legal de los llamados pueblos jóvenes, denominados posteriormente asentamientos humanos y hoy "asentamientos 
informales", son expresamente invasiones de los más pobres que viene desde la década del 50 del siglo pasado (Castro, H. 2007, p. 726); este fenómeno se ha dado hasta la fecha.

\section{En lo territorial y espacial}

El espacio del desierto sur del Perú, no ha recibido la atención de los órganos públicos y estatales; por lo observado, no se ha planificado el uso de suelo, zonificación y monumentación de áreas de protección o intangibles y aquellas aptas para usos determinados, siendo el modelo disperso o semi concentrado en predominante de los centros de servicios rurales, teniendo los siguientes tipos de ocupación: formales y no formales.

Esta actuación espacial representa entre la suma y resta, de lo positivo o negativo concurrente a dicho territorio, un reto al futuro ocupado. El nuevo desafío impuesto por la globalización y los sistemas neoliberales, representan oportunidades nuevas en la actuación sobre el territorio (González, 2011) y la gestión acertada del estado y órganos sectoriales deben posibilitar ello.

\section{En lo ambiental y del paisaje}

El ecosistema desértico, por ocupaciones ilegales de invasiones, está perdiendo su valor agrológico como ecosistema, y su imagen paisajística y escénica natural medio ambiental, con la extinción de líquenes - las tilansiales, este escenario ha sido impactado negativamente con la degradación ambiental de suelos y agua de regadío, presencia de desechos urbanos y aguas servidas sin tratamiento, no se ha reconocido la verdadera dimensión de la problemática del desierto costero sur del Perú, en cuanto a su degradación permanente, y a veces sistemática, generada por agentes ajenos a su planificación y preservación medio ambiental.

\section{AGRADECIMIENTOS}

Al Arq. Saúl César Rolando Durán Arróspide, especialista en planes urbano-territoriales y asentamientos humanos.

Al Arq. Rafael Zavaleta Avalos, especialista en la Oficina de Acondicionamiento Territorial de AUTODEMA.

A1 Dr. Elmer Rivera Mansilla, docente de la UNJBG $\mathrm{y}$ especialista en formulación de estudios de investigación.

\section{REFERENCIAS BIBLIOGRÁFICAS}

Acuña, P. (2000). Fundamentos de planeamiento urbano aspecto técnicos. Lima, Perú: UNI.

Alcaldía de Medellín (2014). Plan de Desarrollo Local, Corregimiento Altavista. Medellín, Colombia.
Azpur, J. (2012). Análisis de la legislación sobre planificación territorial en el Perí. Lima, Perú.

Becerra, G. (2010). E1 corredor inter-oceánico centro: Un Reto a la Preservación Eco-Monumental. Revista AQP, Colegio de Arquitectos del Perú.

Cárdenas, L. (1999). Urbanismo versus Urbanización. Revista de Urbanismo FAU-UCHILE.

Castells, M. (1973). Imperialismo y Urbanización en América Latina. Barcelona, España: Editorial Gustavo Gili, S.A.

Castro, H. (2007). Derecho urbanistico. Lima, Perú: Editora Jurídica Grijley E.I.R.L.

Geddes, P. (1960). Ciudades en Evolución. Buenos Aires, Argentina: Ediciones Infinito.

Golany, G. (1993). Planificación urbana en zonas áridas. México: Editorial Limusa

González, L. (2011). Gestión del Territorio: Un Método para la Intervención Territorial. Chile: UCHILE.

Lynch, K. (1974). Imagen de la ciudad. Buenos Aires, Argentina: Ediciones Infinito.

McLoughlin, J. (1971). Planificación Urbana y Regional Un enfoque de sistemas. Madrid, España: Instituto de Estudios de Administración Local.

Massiris, A. (2012). Ordenamiento Territorial, Región y Procesos de Construcción Regional. Colombia: UPTC.

Meneses, M. (1998). Introducción a la Planificación. Lima, Perú: INCA Publicaciones.

Miró, M. y Morató, M. (1984). En torno la ecogeografía y la planificación territorial. Barcelona, España.

Muñoz, F. (2011). Instrumentos de planificación Territorial del área metropolitana de Concepción y su relación con los Modelos de desarrollo 1960-2011. Chile: UCHILE.

Pulgar, J. (2014). Geografía del Perú: Las ocho regiones naturales del Perú. Sao Paulo, Brasil: Terra Brasilis.

Zegarra, E. (2004). Mercado de aguas: viabilidad y potencialidades de un instrumento para la reforma de la gestión hidrica en el Perú. Lima, Perú. 